\title{
Optimizing feed force for turned parts through the Taguchi technique
}

\author{
HARI SINGH $^{1 *}$ and PRADEEP KUMAR ${ }^{2}$ \\ ${ }^{1}$ Mechanical Engineering Department, National Institute of Technology, \\ Kurukshetra 136 119, India \\ ${ }^{2}$ Department of Mechanical and Industrial Engineering, Indian Institute of \\ Technology, Roorkee 247 667, India \\ *e-mail: hsingh_nitk@ rediffmail.com
}

MS received 16 January 2006; revised 23 April 2006

\begin{abstract}
The objective of the paper is to obtain an optimal setting of turning process parameters (cutting speed, feed rate and depth of cut) resulting in an optimal value of the feed force when machining EN24 steel with TiC-coated tungstencarbide inserts. The effects of the selected turning process parameters on feed force and the subsequent optimal settings of the parameters have been accomplished using Taguchi's parameter design approach. The results indicate that the selected process parameters significantly affect the selected machining characteristics. The results are confirmed by further experiments.
\end{abstract}

Keywords. Cutting parameters; turning process; feed force; Taguchi technique; EN24 steel; coated carbide inserts.

\section{Introduction}

To provide satisfaction to customers and to deliver in a competitive market, a producer has to acknowledge that considerable advantage can be obtained by controlling quality at the design stage itself instead of at the manufacturing stage or by the inspection of finished products. This is basic idea of off-line quality control; Taguchi's method is one of the most comprehensive and effective systems of off-line quality control.

Taguchi has built upon W E Deming's observation that $85 \%$ of poor quality is attributable to the manufacturing process and only $15 \%$ to the worker (Roy 1990). Thus, his attempt has been to develop robust manufacturing systems that are insensitive to daily and seasonal variations of environment, machine wear etc.

Taguchi recommends a three-stage process to achieve desirable product quality by design - system design, parameter design and tolerance design. While system design helps to identify working levels of the design parameters, parameter design seeks to determine parameter levels that provide the best performance of the product or process

*For correspondence 
under study. The optimum condition is selected so that the influence of uncontrollable factors (noise factors) causes minimum variation to system performance. Orthogonal arrays, variance and signal to noise analysis are the essential tools of parameter design. Tolerance design is a step to fine-tune the results of parameter design (Ross 1996).

EN24 is a medium-carbon low-alloy steel and finds its typical applications in the manufacturing of automobile and machine tool parts. Properties of EN24 steel, like low specific heat, and tendency to strain-harden and diffuse between tool and work material, give rise to certain problems in its machining such as large cutting forces, high cutting-tool temperatures, poor surface finish and built-up-edge formation. This material is thus difficult to machine (Mottram \& WoolMan 1966; Nakayama \& Shaw 1967; Komanduri 1982; Sarmah 1988). Nakayama \& Shaw (1967) investigated the machining of EN24 steel with HSS tools and carbide tools. They found large forces during machining which may result in tool fracture and high cutting temperatures. Lo \& Chen (1977) studied tool life in DC hot machining of EN24 steel using carbide tools in the speed range of $35-230 \mathrm{~m} / \mathrm{min}$. They used response surface methodology for design of experiments. Kalnth et al (1978) applied electric resistance heating technique to get optimal results for reduction in cutting forces. They recommended an optimum heating current of 200 amperes for machining EN24 steel at $80 \mathrm{~m} / \mathrm{min}$. Sarmah (1988) carried out some investigations into performance of CVD-coated indexable carbide inserts in machining of austenitic 18-8 stainless steel, incoloy 800 and EN24 alloy steel. The quality of surface finish was found to improve with reduction of cutting force. Abdulla (1994) studied the performance of six coated-carbide inserts in machining of EN24 steel. He used response surface methodology for experimentation. Owing to its wide application EN24 steel has been selected as the work material in this case study. Recently developed tool materials such as coated carbides have improved productivity levels of difficult-to-machine materials.

The literature survey reveals that the machining of difficult-to-machine materials like EN24 is relatively a less researched area. There is also a complete dearth of interaction studies. The objective of this case study is to obtain optimal settings of turning process parameters cutting speed, feed rate and depth of cut, to yield optimal feed force while machining EN24 steel with TiC-coated carbide tools. Taguchi's parameter design approach has been used to accomplish this objective.

\section{Turning process parameters}

In order to identity the process parameters affecting the selected machining quality characteristic of turned parts, an Ishikawa cause-effect diagram was constructed as shown in figure 1. The identified process parameters are the cutting tool parameters - tool geometry, tool material, physical and mechanical properties, the cutting parameters - cutting speed, feed rate, depth of cut, work piece-related parameters - hot-worked, cold-worked, difficult-to-machine, and environment parameters - dry cutting, wet cutting.

The following process parameters were thus selected for the present work: Cutting speed (A), feed rate - (B), depth of cut - (C), tool material - Widadur TG inserts, work material EN24 steel, and environment - dry cutting.

The selection of parameters of interest was based on some preliminary experiments and earlier studies by the authors (Singh \& Kumar 2000, 2003-2005). The following parameters were kept fixed during the entire experimentation: 


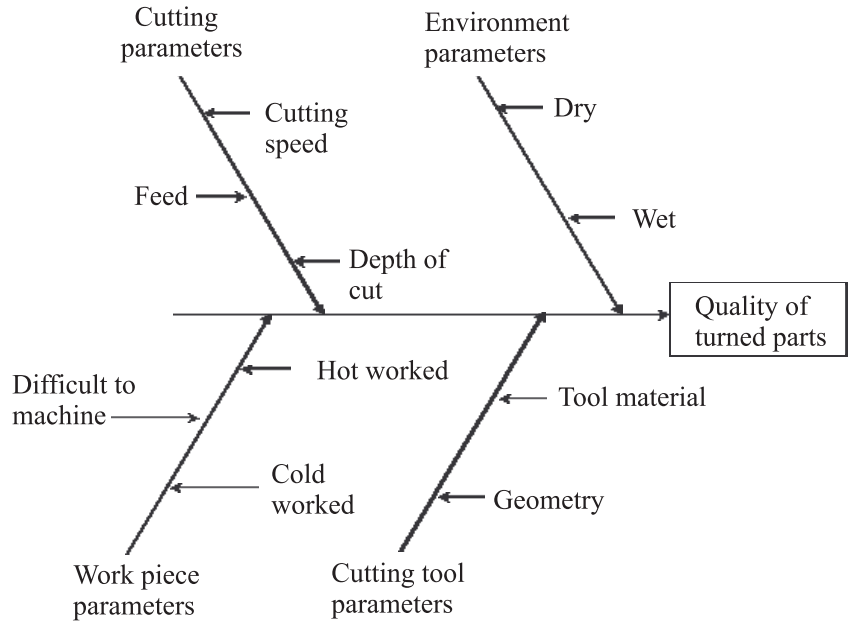

Figure 1. Ishikawa cause-effect diagram of a turning process.
(a) Work material : EN24 steel
(b) Cutting tool material : Widadur TG
(c) Insert geometry : SPUN 120308 (ISO designation)
(d) Tool holder : CSBPR 2525 H 12 (ISO designation)
(e) Cutting conditions : Dry

\section{Selection of orthogonal array $(\mathrm{OA})$}

The nonlinear relationship among the process parameters, if it exists, can only be revealed if more than two levels of the parameters are considered (Byrne \& Taguchi 1987). Thus each selected parameter was analysed at three levels. The process parameters and their values at three levels are given in table 1 .

It was also decided to study the two-factor interaction effects of process parameters on feed force while turning EN24 steel with carbide inserts. Interactions considered were between cutting speed and feed rate $(A \times B)$, feed rate and depth of cut $(B \times C)$, and cutting speed and depth of cut $(\mathrm{A} \times \mathrm{C})$.

The total degrees of freedom (DOF) for three parameters, each at three levels, and the three two-factor interactions are eighteen (Ross 1996). So, a three level OA with at least eighteen DOF was to be selected. The $\mathrm{L}_{27} \mathrm{OA}(\mathrm{DOF}=26)$ was thus selected for the present case study.

Table 1. Process parameters with their values at 3 levels.

\begin{tabular}{clccc}
\hline $\begin{array}{c}\text { Parameters } \\
\text { designation }\end{array}$ & \multicolumn{1}{c}{ Process parameters } & Level 1 & Level 2 & Level 3 \\
\hline A & Cutting speed (m/min) & 190 & 250 & 310 \\
B & Feed rate (mm/rev) & 0.14 & 0.16 & 0.18 \\
C & Depth of cut (mm) & 0.70 & 0.85 & 1.00 \\
\hline
\end{tabular}


Table 2. $\mathrm{L}_{27}\left(3^{13}\right)$ Orthogonal array with process parameters and interactions assigned to columns.

\begin{tabular}{|c|c|c|c|c|c|c|c|c|c|c|c|c|c|}
\hline \multirow[b]{2}{*}{ Trial } & \multicolumn{13}{|c|}{ Column } \\
\hline & $\begin{array}{c}\mathrm{A} \\
1\end{array}$ & $\begin{array}{l}\text { B } \\
2\end{array}$ & $\begin{array}{c}\mathrm{A} \times \mathrm{B} \\
3\end{array}$ & $\underset{4}{\mathrm{~A} \times \mathrm{B}}$ & $\begin{array}{l}\mathrm{C} \\
5\end{array}$ & $\begin{array}{c}\mathrm{A} \times \mathrm{C} \\
6\end{array}$ & $\mathrm{~A} \underset{7}{\times \mathrm{C}}$ & $\begin{array}{c}\mathrm{B} \times \mathrm{C} \\
8\end{array}$ & $\overline{9}$ & $\overline{10}$ & $\begin{array}{c}\mathrm{B} \times \mathrm{C} \\
11\end{array}$ & $\overline{12}$ & - \\
\hline 1 & 1 & 1 & 1 & 1 & 1 & 1 & 1 & 1 & 1 & 1 & 1 & 1 & 1 \\
\hline 2 & 1 & 1 & 1 & 1 & 2 & 2 & 2 & 2 & 2 & 2 & 2 & 2 & 2 \\
\hline 3 & 1 & 1 & 1 & 1 & 3 & 3 & 3 & 3 & 3 & 3 & 3 & 3 & 3 \\
\hline 4 & 1 & 2 & 2 & 2 & 1 & 1 & 1 & 2 & 2 & 2 & 3 & 3 & 3 \\
\hline 5 & 1 & 2 & 2 & 2 & 2 & 2 & 2 & 3 & 3 & 3 & 1 & 1 & 1 \\
\hline 6 & 1 & 2 & 2 & 2 & 3 & 3 & 3 & 1 & 1 & 1 & 2 & 2 & 2 \\
\hline 7 & 1 & 3 & 3 & 3 & 1 & 1 & 1 & 3 & 3 & 3 & 2 & 2 & 2 \\
\hline 8 & 1 & 3 & 3 & 3 & 2 & 2 & 2 & 1 & 1 & 1 & 3 & 3 & 3 \\
\hline 9 & 1 & 3 & 3 & 3 & 3 & 3 & 3 & 2 & 2 & 2 & 1 & 1 & 1 \\
\hline 10 & 2 & 1 & 2 & 3 & 1 & 2 & 3 & 1 & 2 & 3 & 1 & 2 & 3 \\
\hline 11 & 2 & 1 & 2 & 3 & 2 & 3 & 1 & 2 & 3 & 1 & 2 & 3 & 1 \\
\hline 12 & 2 & 1 & 2 & 3 & 3 & 1 & 2 & 3 & 1 & 2 & 3 & 1 & 2 \\
\hline 13 & 2 & 2 & 3 & 1 & 1 & 2 & 3 & 2 & 3 & 1 & 3 & 1 & 2 \\
\hline 14 & 2 & 2 & 3 & 1 & 2 & 3 & 1 & 3 & 1 & 2 & 1 & 2 & 3 \\
\hline 15 & 2 & 2 & 3 & 1 & 3 & 1 & 2 & 1 & 2 & 3 & 2 & 3 & 1 \\
\hline 16 & 2 & 3 & 1 & 2 & 1 & 2 & 3 & 3 & 1 & 2 & 2 & 3 & 1 \\
\hline 17 & 2 & 3 & 1 & 2 & 2 & 3 & 1 & 1 & 2 & 3 & 3 & 1 & 2 \\
\hline 18 & 2 & 3 & 1 & 2 & 3 & 1 & 2 & 2 & 3 & 1 & 1 & 2 & 3 \\
\hline 19 & 3 & 1 & 3 & 2 & 1 & 3 & 2 & 1 & 3 & 2 & 1 & 3 & 2 \\
\hline 20 & 3 & 1 & 3 & 2 & 2 & 1 & 3 & 2 & 1 & 3 & 2 & 1 & 3 \\
\hline 21 & 3 & 1 & 3 & 2 & 3 & 2 & 1 & 3 & 2 & 1 & 3 & 2 & 1 \\
\hline 22 & 3 & 2 & 1 & 3 & 1 & 3 & 2 & 2 & 1 & 3 & 3 & 2 & 1 \\
\hline 23 & 3 & 2 & 1 & 3 & 2 & 1 & 3 & 3 & 2 & 1 & 1 & 3 & 2 \\
\hline 24 & 3 & 2 & 1 & 3 & 3 & 2 & 1 & 1 & 3 & 2 & 2 & 1 & 3 \\
\hline 25 & 3 & 3 & 2 & 1 & 1 & 3 & 2 & 3 & 2 & 1 & 2 & 1 & 3 \\
\hline 26 & 3 & 3 & 2 & 1 & 2 & 1 & 3 & 1 & 3 & 2 & 3 & 2 & 1 \\
\hline 27 & 3 & 3 & 2 & 1 & 3 & 2 & 1 & 2 & 1 & 3 & 1 & 3 & 2 \\
\hline
\end{tabular}

The $\mathrm{L}_{27} \mathrm{OA}$ is given in table 2. This array specifies twenty-seven experimental runs and has thirteen columns. Using a linear graph for $\mathrm{L}_{27} \mathrm{OA}$ (Peace 1993), the interacting columns were identified and parameters were assigned to specific columns accordingly. The assignment of process parameters and interactions to columns is also done in table 2 .

\section{Experiment, analysis and discussion}

EN24 steel rods of $90 \mathrm{~mm}$ diameter and $500 \mathrm{~mm}$ length were turned on an H-22 centre lathe (HMT). Titanium carbide-coated tungsten carbide inserts (Widia India Limited) were used to machine the work material (EN24 steel) of mean hardness $220 \mathrm{BHN}$. Three specimens were turned for each trial condition given in table 2. Using the randomization technique, eightyone specimens were thus turned and the feed force was measured with a three-dimensional turning dynamometer, with four extended half rings machined from a single block of CI. The tangential force places the lower elements of half rings under compression and the upper ones under tension. The feed force subjects all elements to shearing while the radial force subjects all the half rings to compression. The dynamometer was calibrated on a vertical milling machine by using a proving ring. The calibration curve is shown in figure 2 . 


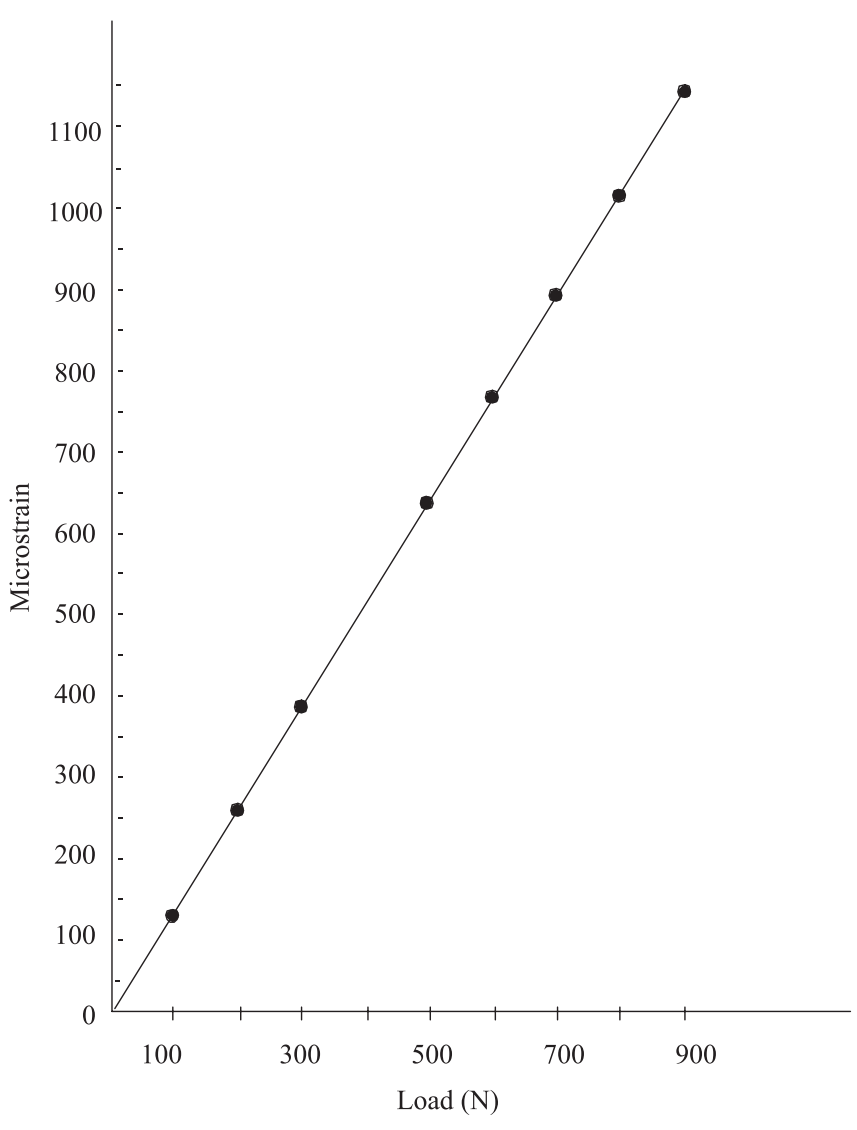

Figure 2. Calibration curve for tool dynamometer - feed force

Experimental data for the feed force have been reported in table 3. Feed force being a 'lower the better' type of machining quality characteristic, the $S / N$ ratio for this type of response was used and is given below (Roy 1990).

$$
S / N \text { ratio }(\mathrm{dB})=-10 \log \left[\frac{1}{n}\left(y_{1}^{2}+y_{2}^{2}+\cdots+y_{n}^{2}\right)\right],
$$

where $y_{1}, y_{2}, \ldots, y_{n}$ are the responses of the machining characteristic, the feed force, for a trial condition repeated $n$ times. The $S / N$ ratios were computed using (1) for each of the twenty-seven trials and the values are reported in table 3 along with the raw data for feed force.

The mean response refers to the average value of the performance characteristic for each parameter at different levels. The average values of feed force for each parameter at levels 1, 2 and 3 are calculated and given in table 4 . The main effects, i.e. the effects of process parameters on the response characteristic when the process parameters change from one level to another are also given in table 4 and are plotted in figures $3 \mathrm{a}-\mathrm{c}$. The average values of $S / N$ ratios of various parameters at different levels are reported in table 5 and plotted in figures $3 \mathrm{a}-\mathrm{c}$ along with the raw data. The interaction graphs, both for raw data and $S / N$ data, are plotted in figures $4 \mathrm{a}-\mathrm{c}$. 
Table 3. Experimental data of feed force.

\begin{tabular}{|c|c|c|c|c|}
\hline \multirow[b]{2}{*}{ Trial No. } & \multicolumn{3}{|c|}{ Feed force $(\mathrm{N})$} & \multirow[b]{2}{*}{$S / N$ ratio $(\mathrm{dB})$} \\
\hline & $\mathrm{R} 1$ & $\mathrm{R} 2$ & R3 & \\
\hline 1 & 210 & 190 & 190 & $-45 \cdot 88$ \\
\hline 2 & 205 & 185 & 210 & $-46 \cdot 03$ \\
\hline 3 & 240 & 215 & 215 & -46.99 \\
\hline 4 & 200 & 205 & 205 & $-46 \cdot 16$ \\
\hline 5 & 230 & 250 & 215 & -47.31 \\
\hline 6 & 250 & 240 & 250 & -47.84 \\
\hline 7 & 225 & 200 & 220 & $-46 \cdot 66$ \\
\hline 8 & 245 & 255 & 235 & -47.79 \\
\hline 9 & 275 & 250 & 235 & -48.09 \\
\hline 10 & 185 & 175 & 190 & $-45 \cdot 27$ \\
\hline 11 & 240 & 190 & 205 & $-46 \cdot 56$ \\
\hline 12 & 240 & 190 & 175 & $-46 \cdot 17$ \\
\hline 13 & 175 & 195 & 190 & $-45 \cdot 43$ \\
\hline 14 & 250 & 210 & 230 & $-47 \cdot 26$ \\
\hline 15 & 230 & 230 & 190 & $-46 \cdot 75$ \\
\hline 16 & 190 & 210 & 215 & $-46 \cdot 25$ \\
\hline 17 & 280 & 240 & 255 & $-48 \cdot 26$ \\
\hline 18 & 240 & 220 & 255 & -47.56 \\
\hline 19 & 185 & 170 & 175 & -44.95 \\
\hline 20 & 190 & 190 & 200 & -45.73 \\
\hline 21 & 250 & 260 & 230 & -47.85 \\
\hline 22 & 195 & 175 & 180 & $-45 \cdot 27$ \\
\hline 23 & 215 & 220 & 210 & $-46 \cdot 65$ \\
\hline 24 & 235 & 250 & 240 & -47.67 \\
\hline 25 & 200 & 185 & 190 & $-45 \cdot 66$ \\
\hline 26 & 230 & 235 & 235 & $-47 \cdot 36$ \\
\hline 27 & 290 & 255 & 250 & $-48 \cdot 48$ \\
\hline Total & 6100 & 5790 & 5790 & \\
\hline
\end{tabular}

$\bar{T}_{F F}=$ overall mean of feed force $=218 \cdot 27 \mathrm{~N}$

\subsection{Analysis of results}

It is evident from the figure 3 that feed force is minimum at the first level of feed (B) and the first level of depth of cut $(\mathrm{C})$. The effect of cutting speed is not very clearly defined in figure $3 \mathrm{a}$.

The interaction analysis in figure 4 clearly shows that $B_{1} C_{1}$ and $A_{3} C_{1}$ are the optimal combinations. Thus, the third level of cutting speed, first level of feed and first level of depth of cut represent the optimal levels of various turning process parameters to yield an optimal value of the feed force.

In order to quantify the influence of process parameters and interactions on the selected machining characteristic, the feed force, analysis of variance (ANOVA) was performed. The pooled ANOVA of the raw data (feed force) is given in table 6 . The $S / N$ pooled ANOVA is given in table 7.

It is evident from the pooled ANOVA tables 6 and 7 for raw data and $S / N$ data that feed rate, depth of cut and interaction between cutting speed and depth of cut $(\mathrm{A} \times \mathrm{C})$, are all significant at $95 \%$ confidence level in both ANOVAs, and thus affect the average value of feed force as 
Table 4. Average values and main effects (raw data: feed force).

\begin{tabular}{|c|c|c|c|c|c|}
\hline \multirow{2}{*}{$\begin{array}{l}\text { Process } \\
\text { parameter } \\
\text { designation }\end{array}$} & \multicolumn{3}{|c|}{ Average values of feed force $(\mathrm{N})$} & \multicolumn{2}{|c|}{ Main effects $(\mathrm{N})$} \\
\hline & L1 & $\mathrm{L} 2$ & L3 & L2-L1 & L3-L2 \\
\hline A & $223 \cdot 9$ & $214 \cdot 6$ & $216 \cdot 3$ & $-9 \cdot 3$ & $1 \cdot 7$ \\
\hline B & 203.7 & $217 \cdot 2$ & 233.9 & $13 \cdot 5$ & $16 \cdot 7$ \\
\hline $\mathrm{C}$ & 193.5 & $224 \cdot 3$ & 237 & $30 \cdot 8$ & 12.7 \\
\hline$A \times B$ & $216 \cdot 9$ & $220 \cdot 5$ & $217 \cdot 4$ & 3.6 & $-3 \cdot 1$ \\
\hline $\mathrm{B} \times \mathrm{C}$ & $221 \cdot 6$ & $214 \cdot 3$ & 219 & $-7 \cdot 3$ & $4 \cdot 7$ \\
\hline $\mathrm{A} \times \mathrm{C}$ & $221 \cdot 2$ & $216 \cdot 1$ & $217 \cdot 5$ & $-5 \cdot 1$ & 1.4 \\
\hline
\end{tabular}

well as its variation. Cutting speed (A) and the interaction between feed rate and depth of cut $(\mathrm{B} \times \mathrm{C})$ are significant at $95 \%$ confidence level in $S / N$ pooled ANOVA only, thus affecting the only variation in feed force. The ANOVAs also suggest that the interaction between cutting speed and feed rate $(\mathrm{A} \times \mathrm{B})$ is insignificant and does not affect anything (Ross 1996).

The percent contributions of parameters as quantified under column $P$ of tables 6 and 7 reveal that the influence of depth of cut in affecting feed force is significantly larger than the

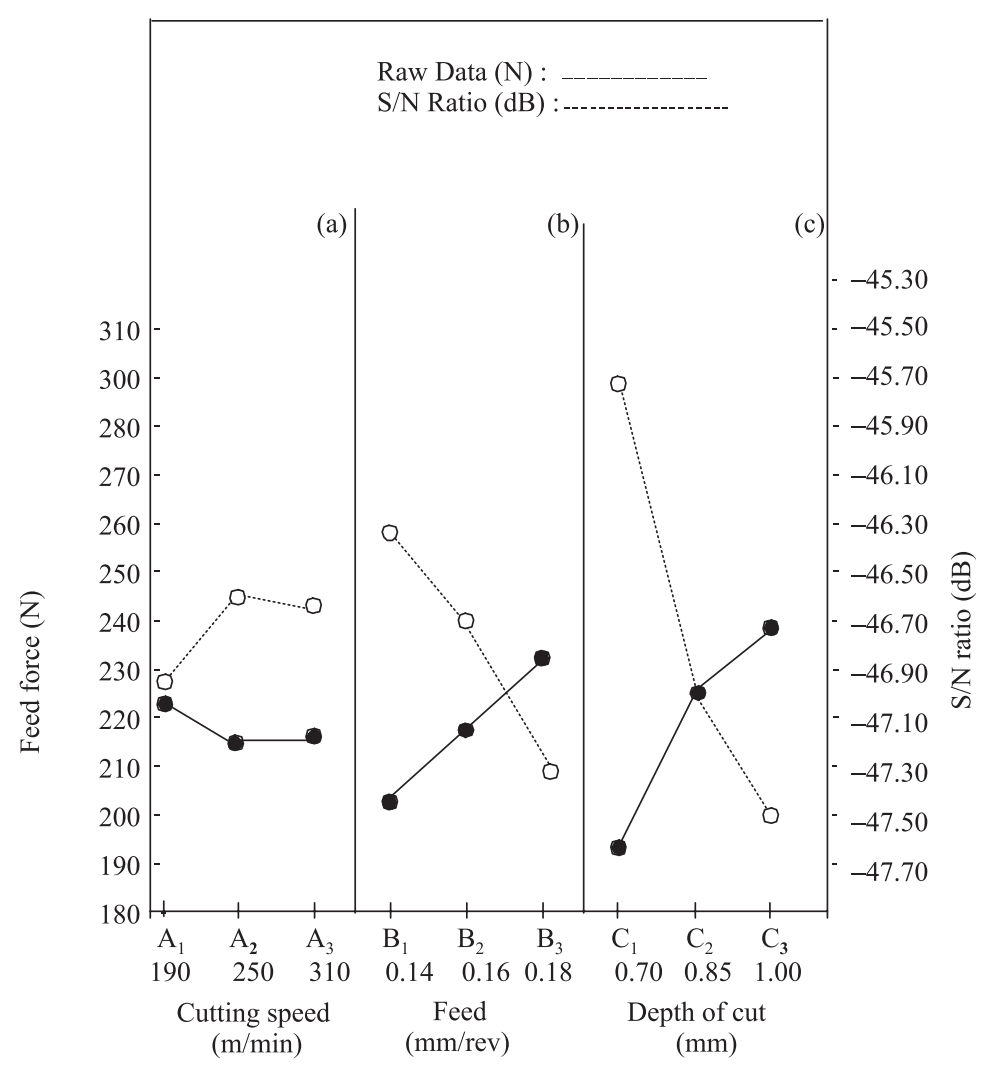

Figure 3. Effects of process parameters on feed force (raw data) and $S / N$ ratio. (a) Cutting speed, (b) feed, (c) depth of cut. 
Table 5. $S / N$ average values and main effects (raw data: feed force).

\begin{tabular}{lcccccc}
\hline $\begin{array}{l}\text { Process } \\
\text { paramete } \\
\text { designation }\end{array}$ & \multicolumn{3}{c}{$S / N$ average values $(\mathrm{dB})$} & & \multicolumn{2}{c}{ Main effects $(\mathrm{dB})$} \\
\cline { 2 - 4 } & $\mathrm{L} 1$ & $\mathrm{~L} 2$ & $\mathrm{~L} 3$ & & L2-L1 & L3-L2 \\
\hline A & -46.97 & -46.61 & -46.62 & & 0.36 & -0.01 \\
$\mathrm{~B}$ & -46.16 & -46.71 & -47.35 & & -0.55 & -0.64 \\
$\mathrm{C}$ & -45.73 & -46.99 & -47.49 & & -1.26 & -0.5 \\
$\mathrm{~A} \times \mathrm{B}$ & -46.69 & -46.82 & -46.70 & & -0.13 & 0.12 \\
$\mathrm{~B} \times \mathrm{C}$ & -46.85 & -46.58 & -46.78 & & 0.27 & -0.2 \\
$\mathrm{~A} \times \mathrm{C}$ & -46.87 & -46.64 & -46.69 & & 0.23 & -0.05 \\
\hline
\end{tabular}

feed rate, cutting speed and interaction between cutting speed and depth of cut. It is also clear from table 6 that the relative strength of the interaction between cutting speed and depth of cut $(A \times C: 10.23 \%)$ is significant as compared with the relative strength of feed rate (B: 18.75\%)

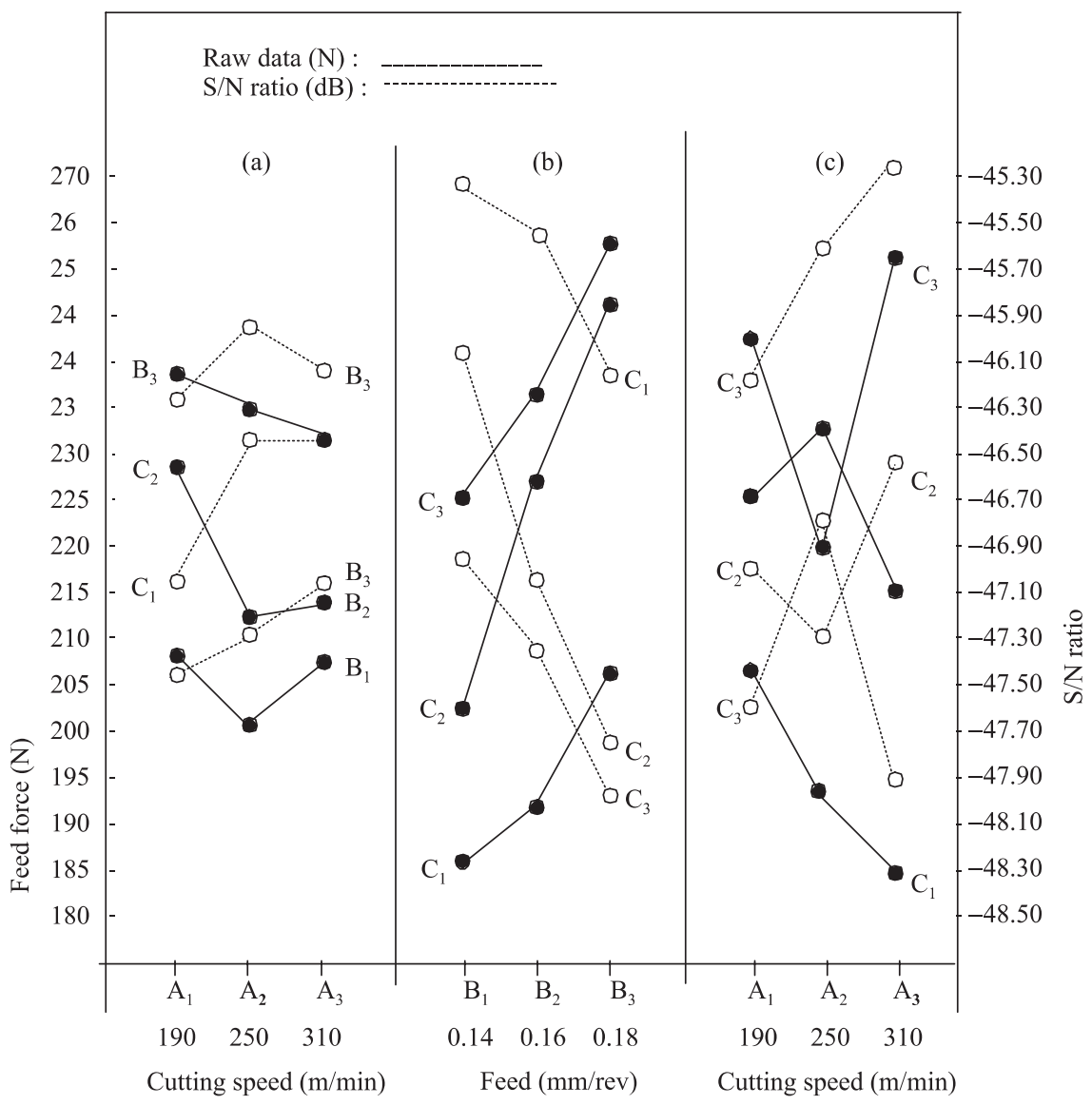

Figure 4. Effects of process parameters interactions on feed force (raw data) and $S / N$ ratio. (a) and (c) Cutting speed, (b) feed. 
Table 6. Pooled ANOVA (raw data: feed force).

\begin{tabular}{|c|c|c|c|c|c|c|}
\hline Source & SS & DOF & V & $F$ ratio & $\mathrm{SS}^{\prime}$ & $\mathrm{P}$ \\
\hline A & (1315.4) & (2) & - & Pooled & - & - \\
\hline B & 12345 & 2 & $6172 \cdot 5$ & $26 \cdot 39^{*}$ & $11916 \cdot 948$ & 18.75 \\
\hline $\mathrm{C}$ & 27019 & 2 & $13509 \cdot 5$ & $57 \cdot 77^{*}$ & $26590 \cdot 948$ & 41.84 \\
\hline$A \times B$ & $(647 \cdot 5)$ & (4) & - & Pooled & - & - \\
\hline$B \times C$ & (1604.9) & (4) & - & Pooled & - & - \\
\hline $\mathrm{A} \times \mathrm{C}$ & $7356 \cdot 6$ & 4 & $1839 \cdot 15$ & $7 \cdot 86^{*}$ & $6500 \cdot 4968$ & $10 \cdot 23$ \\
\hline $\mathrm{T}$ & 63558 & 80 & & & 63558 & $100 \cdot 00$ \\
\hline e (pooled) & $(16837 \cdot 4)$ & (72) & 233.85278 & & $18549 \cdot 606$ & $29 \cdot 18$ \\
\hline
\end{tabular}

$\mathrm{SS}=$ sum of squares, $\mathrm{DOF}=$ degrees of freedom, $\mathrm{V}=$ variance, $\mathrm{T}=$ total; $\mathrm{SS}^{\prime}=$ pure sum of squares, $\mathrm{P}=$ percent contribution, $\mathrm{e}=$ error, Tabulated $F$-ratio at $95 \%$ confidence level: $F_{0 \cdot 05 ; 2 ; 72}=$ $3 \cdot 13 ; F_{0} \cdot 05 ; 4 ; 72=2 \cdot 50$

* Significant at $95 \%$ confidence level

and depth of cut (C: $41.84 \%)$. Thus, to estimate mean value, the interaction between cutting speed and depth of cut $(\mathrm{A} \times \mathrm{C})$ is also considered. The parameters and their selected levels are given in table 8 .

\section{Estimation of optimum value of feed force}

To obtain the best estimate of a mean value when there is an interaction, trials that include the specific treatment condition (here, $\mathrm{A}_{3} \mathrm{C}_{1}$ ) should be averaged. By considering the interaction as one item that has good additivity to other non-interacting items (here, $\mathrm{B}_{1}$ ), an estimate of mean value may be made (Ross 1996).

From table 2, it is clear that the $A_{3} C_{1}$ combination is included in the trials 19,22 and 25. These trials are thus averaged to get, $\overline{\mathrm{A}_{3} \mathrm{C}_{1}}=183.89 \mathrm{~N}$ (table 3 ).

The estimated mean of the response characteristic can be computed as (Ross 1996):

$$
\mu_{F F}=\overline{\mathrm{A}_{3} \mathrm{C}_{1}}+\overline{B_{1}}-\overline{T_{F F}}
$$

Table 7. $S / N$ pooled ANOVA (raw data: feed force).

\begin{tabular}{|c|c|c|c|c|c|c|}
\hline Source & SS & DOF & V & $F$ ratio & $\mathrm{SS}^{\prime}$ & $\mathrm{P}$ \\
\hline A & 0.764 & 2 & $0 \cdot 382$ & $8.90^{*}$ & 0.70775 & 2.63 \\
\hline B & $6 \cdot 337$ & 2 & $3 \cdot 1685$ & $73 \cdot 83^{*}$ & $6 \cdot 28075$ & $23 \cdot 33$ \\
\hline $\mathrm{C}$ & 14.904 & 2 & $7 \cdot 452$ & $173.64^{*}$ & 14.84775 & $55 \cdot 15$ \\
\hline $\mathrm{A} \times \mathrm{B}$ & $(0 \cdot 290)$ & (4) & & Pooled & - & - \\
\hline$B \times C$ & 0.712 & 4 & $0 \cdot 178$ & $4 \cdot 15^{*}$ & 0.5995 & $2 \cdot 23$ \\
\hline $\mathrm{A} \times \mathrm{C}$ & 3.692 & 4 & 0.923 & $21 \cdot 51^{*}$ & $3 \cdot 5795$ & $13 \cdot 29$ \\
\hline $\mathrm{T}$ & 26.924 & 26 & & & 26.924 & 100.00 \\
\hline e (pooled) & $(0.515)$ & (12) & $7 \cdot 0429166$ & & 0.90875 & 3.37 \\
\hline
\end{tabular}

Tabulated F-ratio at $95 \%$ confidence level: $F_{0.05 ; 2 ; 12}=3.89 ; F_{0.05 ; 4: 12}=3.26$

*Significant at $95 \%$ confidence level. 
Table 8. Parameters and their selected levels (for optimal feed force).

\begin{tabular}{cll}
\hline $\begin{array}{c}\text { Parameter } \\
\text { designation }\end{array}$ & Process parameters & Optimal levels \\
\hline A & Cutting speed & $3(310 \mathrm{~m} / \mathrm{min})$ \\
B & Feed rate & $1(0 \cdot 14 \mathrm{~mm} / \mathrm{rev})$ \\
C & Depth of cut & $1(0 \cdot 70 \mathrm{~mm})$ \\
\hline
\end{tabular}

where $\overline{T_{F F}}=$ overall mean of feed force $=218.27 \mathrm{~N}$ (table 3 ) and $\bar{B}_{1}=$ average value of feed force at the first level of feed $=203.7 \mathrm{~N}$ (table 4).

Hence $\mu_{F F}=169 \cdot 32 \mathrm{~N}$.

A confidence interval for the predicted mean on a confirmation run can be calculated using the following equation (Ross 1996):

$$
\mathrm{CI}=\left(F_{\alpha ;\left(1, f_{e}\right)} V_{e}\left[\frac{1}{n_{\mathrm{eff}}}+\frac{1}{R}\right]\right)^{1 / 2},
$$

where $F_{\alpha:}\left(1, f_{e}\right)=F$ ratio required for $\alpha, \alpha=$ risk, $f_{e}=$ error DOF, $V_{e}=$ error variance, $n_{\text {eff }}=$ effective number of replications $=N /\{1+[$ Total DOF associated in the estimate of mean]\},

$R=$ number of repetitions for confirmation experiment, $N=$ total number of experiments.

Using the values $V_{e}=233.85278$ and $f_{e}=72$ from table 6 , the confidence interval is calculated.

Total DOF associated with the mean $\left(\mu_{F F}\right)=2 \times 2+2=6$, total trials $=27, N=$ $3 \times 27=81$

$$
n_{\text {eff }}=81 /(1+6)=11 \cdot 57, \alpha=0 \cdot 05, F_{0 \cdot 05 ;(1,72)}=3.98 \text { (tabulated). }
$$

The calculated CI is: $\mathrm{CI}= \pm 19.77$.

The predicted mean of feed force is: $\mu_{F F}=169 \cdot 32 \mathrm{~N}$.

The 95\% confidence interval of the predicted optimal feed force is: $\left[\mu_{F F}-\mathrm{CI}\right]<\mu_{F F}<$ $\left[\mu_{F F}+\mathrm{CI}\right]$ i.e. $149.55<\mu_{F F}(\mathrm{~N})<189.09$.

\section{Confirmation experiments}

The confirmation experiment is the final step in verifying the conclusions drawn based on Taguchi's parameter design approach. The optimum conditions are set for the significant factors (the insignificant factors are set at economic levels) and a selected number of tests are run under constant specified conditions. The average of the results of the confirmation experiment is compared with the anticipated average based on the parameters and levels tested. The confirmation experiment is a crucial step and is highly recommended by Taguchi to verify the experimental conclusions (Ross 1996). Three confirmation experiments were thus conducted at the optimal settings of the turning process parameters recommended by the investigation. The average value of feed force while turning EN24 steel with TiC-coated carbide inserts was found to be $176.67 \mathrm{~N}$. This result was within the $95 \%$ confidence interval of the predicted optimal value of the selected machining characteristic (feed force). Hence the optimal settings of the process parameters, as predicted in the analysis, can be implemented. 


\section{Limitations of case study}

The results are valid within the specified range of the process parameters and for the specified work-tool combination. Any extrapolation must be confirmed by experiments.

\section{Conclusions}

The following conclusions can be drawn from the case study.

(1) The percent contributions of depth of cut $(55.15 \%)$ and feed rate $(23.33 \%)$ in affecting the variation of feed force are significantly larger ( $95 \%$ confidence level) as compared to the contribution of the cutting speed $(2.63 \%)$.

(2) Interaction between cutting speed and depth of cut is significant at $95 \%$ confidence level in affecting the mean and variation of feed force, while the interaction between feed and depth of cut affects only the variation in the feed force.

(3) Optimal settings of various process parameters for turned parts to yield optimal feed force are: cutting speed $=310 \mathrm{~m} / \mathrm{min}$; feed rate $=0.14 \mathrm{~mm} / \mathrm{rev}$; depth of cut $=0.70 \mathrm{~mm}$.

(4) The predicted range of the optimal feed force is:

$$
149.55<\mu_{F F}(\mathrm{~N})<189.09
$$

\section{References}

Abdulla A A 1994 Performance of some coated carbide inserts in machining of EN24 steel. Ph D thesis, University of Roorkee, Roorkee

Byrne D M, Taguchi S 1987 The Taguchi approach to parameter design. Quality Progress: 19-26

Kalnth G S, Sachdeva S C, Choudhary A P 1978 An experimental investigation into hot machining of EN24 steel. Proc. AIMTDR Conference, IIT, Bombay, p. 285

Komanduri R 1982 Catastrophic shear instability in high speed machining of AISI 4340 steels. Trans. ASME., J. Eng. Ind. 104: 121-128

Lo K C, Chen N S S 1977 Prediction of tool life in hot machining of alloy steels. Int. J. Prod. Res. 15: 47-63

Mottram R A, WoolMan J 1966 The mechanical and physical properties of the British Standard EN steels vol. 2, EN21-EN39, p. 72

Nakayama K, Shaw M C 1967 Machining high strength materials. Ann. CIRP 15: 456-459

Peace G S 1993 Taguchi methods: A hands-on approach (New York: Addison Wesley)

Roy R K 1990 A primer on Taguchi method (New York: Van Nostrand Reinhold)

Ross P J 1996 Taguchi techniques for quality engineering (New York: McGraw-Hill)

Sarmah B P 1988 Some investigations into performance of CVD-coated indexable carbide inserts in machining of difficult to machine materials. Ph D thesis, University of Roorkee, Roorkee

Singh H, Kumar P 2000 Multicriteria optimization of machining parameters using the concept of fuzzy set logics. Proc. 16th Nat. Convention of Mechanical Engineers University of Roorkee, Roorkee, India, pp. 516-521

Singh H, Kumar P 2003 Quality optimization of turned parts (En 24 steel) by Taguchi method. Prod. J. 44: 43-49

Singh H, Kumar P 2004 Tool wear optimization in turning operation by Taguchi method. Indian J. Eng. Mater. Sci. 11: 19-24

Singh H, Kumar P 2004 Effect on power consumption for turned parts using Taguchi technique. Prod. J. 45: 231-238

Singh H, Kumar P 2005 Optimizing cutting force for turned parts using Taguchi's parameter design approach. Indian J. Eng. Mater. Sci. 12: 97-103 